\title{
NEUTRON INDUCED REACTIONS ON RADIOACTIVE BERYLLIUM AND ARGON ISOTOPES
}

\author{
C. WAGEMANS AND G. GOEMINNE \\ University of Gent, Dept. of Subatomic and Radiation Physics, B-9000 Gent, Belgium \\ E-mail:wagemans@irmm.jrc.be \\ J. WAGEMANS \\ EC, JRC, Institute for Reference Materials and Measurements, B-2440 Geel, Belgium \\ U. KÖSTER \\ CERN-ISOLDE, CH-1211 Geneva, Switzerland \\ M. LOISELET AND M. GAELENS \\ University of Louvain, Cyclotron Research Center, B-1348 Louvain-la-Neuve, Belgium \\ P. GELTENBORT \\ Institute Laue-Langevin, BP 156, F-38042 Grenoble, France \\ The preparation of radioactive ${ }^{10} \mathrm{Be},{ }^{37} \mathrm{Ar}$ and ${ }^{39} \mathrm{Ar}$ samples is discussed. Investigation of the \\ ${ }^{10} \mathrm{Be}\left(\mathrm{n}_{\mathrm{th}}, \gamma\right){ }^{11} \mathrm{Be},{ }^{37} \mathrm{Ar}\left(\mathrm{n}_{\mathrm{th}}, \alpha\right){ }^{34} \mathrm{~S},{ }^{37} \mathrm{Ar}\left(\mathrm{n}_{\mathrm{th}}, \mathrm{p}\right){ }^{37} \mathrm{Cl}$ and ${ }^{39} \mathrm{Ar}\left(\mathrm{n}_{\mathrm{th}}, \alpha\right){ }^{36} \mathrm{~S}$ reactions is reported, and \\ resonances in the ${ }^{37} \operatorname{Ar}(n, \alpha){ }^{34} \mathrm{~S}$ reaction have been observed and analysed.
}

\section{Introduction}

Radioactive beams are used for a large variety of nuclear reaction studies, but a direct interaction with a neutron beam has not been realised so far. In the present paper we discuss a two-step method, in which rare radioactive nuclides are produced, ionised, accelerated and implanted in a foil, which then is bombarded with neutrons.

This method was applied recently at the cyclotron of the UCL (Louvain-laNeuve, Belgium), where ${ }^{37} \mathrm{Ar}$ (half-life 35.04 days) was produced, and at CERNISOLDE (Geneva, Switzerland), where ${ }^{10} \mathrm{Be}$ (half-life 1.6 million years) and ${ }^{39} \mathrm{Ar}$ (half-life 269 years) samples were made. These samples were then irradiated with thermal neutrons at the high flux reactor of the ILL (Grenoble, France); some of the ${ }^{37} \mathrm{Ar}$ samples were also used for measurements with resonance neutrons at the GELINA neutron facility in Geel (Belgium).

open-2002-003.doc submitted to World Scientific 1/14/2002 : 5:06 PM 


\section{Sample preparation and characterisation}

The ${ }^{37} \mathrm{Ar}$ samples were produced via the ${ }^{37} \mathrm{Cl}(\mathrm{p}, \mathrm{n})^{37} \mathrm{Ar}$ reaction using a $30 \mathrm{MeV}$ proton beam of the CYCLONE 30 cyclotron of the UCL. Up to $7 \times 10^{15}{ }^{37} \mathrm{Ar}$ ions could be implanted in thin aluminium foils. The number of atoms was determined by measuring the $2.62 \mathrm{keV}$ KX-rays emitted during the EC-decay of ${ }^{37} \mathrm{Ar}$. A detailed description of the procedure can be found in [1].

${ }^{10} \mathrm{Be}$ and ${ }^{39} \mathrm{Ar}$ on the other hand were produced via spallation reactions on graphite and titaniumoxide respectively, induced by $1 \mathrm{GeV}$ protons of CERN's PS booster. Then the reaction products were ionised and mass-analysed at ISOLDE and implanted in a $\mathrm{Ge}$ and $\mathrm{Al}$ strip, respectively. In this way, a ${ }^{10} \mathrm{Be}$ sample containing $10^{15}$ atoms and a ${ }^{39} \mathrm{Ar}$ sample containing $3 \times 10^{14}$ atoms were obtained. The number of atoms was determined by counting the $0.6 \mathrm{MeV} \beta$-particles emitted in the decay of both ${ }^{10} \mathrm{Be}$ and ${ }^{39} \mathrm{Ar}$.

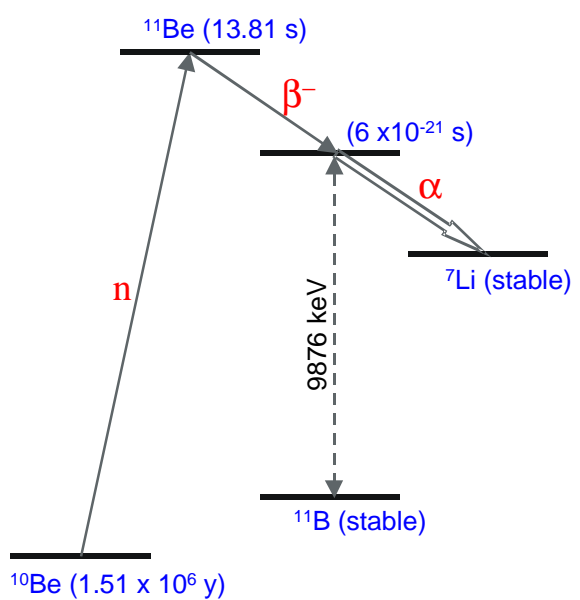

Figure 1. Schematic representation of the ${ }^{10} \mathrm{Be}\left(\mathrm{n}_{\mathrm{th}}, \gamma\right)^{11} \mathrm{Be}\left(\beta^{-}\right)^{11} \mathrm{~B} *(\alpha)^{7} \mathrm{Li}$ process.

\section{Measurements and results}

All measurements with thermal neutrons were performed at the ILL's curved neutron guide H22D, where a vacuum chamber with suited surface-barrier detectors was installed. A very clean thermal neutron beam with $3.5 \times 10^{8}$ neutrons $/ \mathrm{cm}^{2}$.s was hitting the sample. Measurements with resonance neutrons were only performed for ${ }^{37} \mathrm{Ar}$. These experiments were carried out at a $8 \mathrm{~m}$ long flight-path of the GELINA neutron facility. The charged particles were detected using a Frisch-gridded ionisation chamber with a methane gas-flow. 


\section{$3.1{ }^{10} \mathrm{Be}$}

The ${ }^{10} \mathrm{Be}$ sample was used to determine the cross section of the ${ }^{10} \mathrm{Be}\left(\mathrm{n}_{\mathrm{th}}, \gamma\right){ }^{11} \mathrm{Be}$ reaction leading to the halo nucleus ${ }^{11} \mathrm{Be}$. Due to the small number of atoms, this was done in an indirect way, i.e. via the detection of the $0.77 \mathrm{MeV} \alpha$-particles emitted in the ${ }^{10} \mathrm{Be}\left(\mathrm{n}_{\mathrm{th}}, \gamma\right){ }^{11} \mathrm{Be}\left(\beta^{-}\right)^{11} \mathrm{~B}^{*}(\alpha)^{7} \mathrm{Li}$ processes (Figure 1). We know indeed that the $\alpha$-decay from the short-living $9.876 \mathrm{MeV}$ level in ${ }^{11} \mathrm{~B}$ to the ${ }^{7} \mathrm{Li}$ ground state has a branching ratio of $2.7 \%$ [2], so the ${ }^{10} \mathrm{Be}\left(\mathrm{n}_{\mathrm{th}}, \gamma\right)^{11} \mathrm{Be}$ cross section can immediately be deduced from this "quasi $(n, \alpha)$ " experiment. The measurement was hampered by the presence of a small amount of ${ }^{10} \mathrm{~B}$ in the Ge strip, the ${ }^{10} \mathrm{~B}\left(\mathrm{n}_{\mathrm{th}}, \alpha\right){ }^{7} \mathrm{Li}$ reaction having a very large cross section $\left(3840\right.$ b). So a disturbing ${ }^{7} \mathrm{Li}$ peak appeared at $0.83 \mathrm{MeV}$, its tail hampering a clean detection of the $0.77 \mathrm{MeV} \alpha$ 's. As a result, we could only determine an upper-limit of $5 \mathrm{~b}$ for the ${ }^{10} \mathrm{Be}\left(\mathrm{n}_{\mathrm{th}}, \gamma\right){ }^{11} \mathrm{Be}$ cross section. This measurement however demonstrated the feasibility of the method, significant improvements being possible: (1) ${ }^{10} \mathrm{Be}$ atoms could be implanted in ultrapure $\mathrm{Al}$, solving the ${ }^{10} \mathrm{~B}$ problem; (2) a more intense neutron beam could be used and (3) the detection efficiency could be increased.
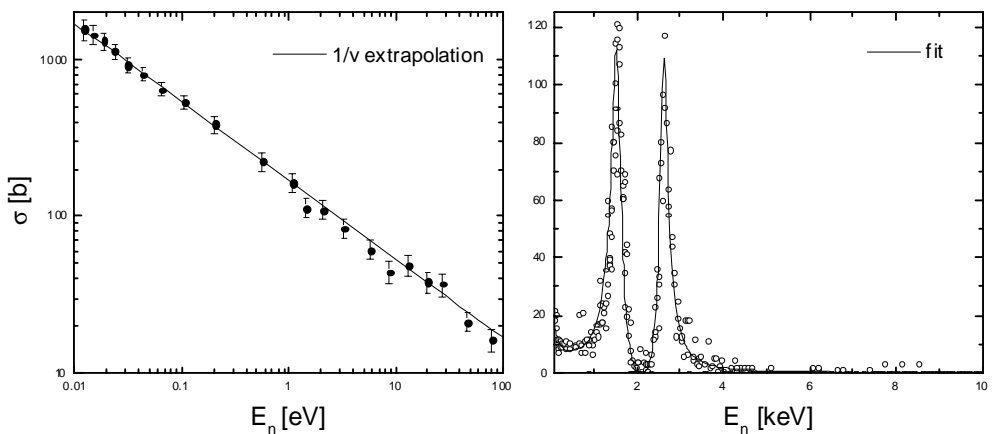

Figure 2. $\operatorname{The}{ }^{37} \operatorname{Ar}(\mathrm{n}, \alpha)^{34} \mathrm{~S}$ cross section from $0.01 \mathrm{eV}$ to $10 \mathrm{keV}$.

\section{$3.2{ }^{37} \mathrm{Ar}$}

The ${ }^{37} \operatorname{Ar}(n, p){ }^{37} \mathrm{Cl}$ and ${ }^{37} \operatorname{Ar}(n, \alpha){ }^{34} \mathrm{~S}$ reactions were investigated with thermal and with resonance neutrons, ${ }^{37} \mathrm{Ar}$ being one of the few nuclides with positive reaction energies for both $(n, p)$ and $(n, \alpha)$ reactions. Moreover, the capture of a neutron leads to the semi-double-magic nucleus ${ }^{38} \mathrm{Ar}$, for which no resonance data exist.

The measurements with thermal neutrons resulted in the following cross sections: ${ }^{37} \operatorname{Ar}\left(\mathrm{n}_{\mathrm{th}}, \alpha_{0}\right){ }^{34} \mathrm{~S} \quad(1070 \pm 80) \mathrm{b} ;{ }^{37} \operatorname{Ar}\left(\mathrm{n}_{\mathrm{th}}, \alpha_{1}\right){ }^{34} \mathrm{~S} \quad(0.31 \pm 0.10) \mathrm{b} ;{ }^{37} \operatorname{Ar}\left(\mathrm{n}_{\mathrm{th}}, \mathrm{p}\right){ }^{37} \mathrm{Cl}$ $(37 \pm 4) b$ [3]. These values are two times smaller than those of Asghar et al. [4].

open-2002-003.doc submitted to World Scientific 1/14/2002 : 5:06 PM 
Experiments performed at GELINA covered the neutron energy region from 0.01 $\mathrm{eV}$ up to $100 \mathrm{keV}$. The ${ }^{37} \mathrm{Ar}(\mathrm{n}, \alpha)^{34} \mathrm{~S}$ cross section was shown to have a $1 / \mathrm{v}$-shape (figure 2 left), and in the $\mathrm{keV}$ region several resonances were observed (figure 2 right) and analysed.

\section{$3.3{ }^{39} \mathrm{Ar}$}

For the ${ }^{39} \operatorname{Ar}\left(n_{\mathrm{th}}, \alpha\right){ }^{36} \mathrm{~S}$ reaction cross section, a theoretical estimate of $3.5 \mathrm{~b}$ can be deduced from the data of Woosley et al. [6]. In the present work, a much lower upper-limit of $260 \mathrm{mb}$ is obtained.

\section{Discussion}

The present study of the ${ }^{37} \operatorname{Ar}(\mathrm{n}, \alpha){ }^{34} \mathrm{~S},{ }^{37} \mathrm{Ar}(\mathrm{n}, \mathrm{p}){ }^{37} \mathrm{Cl}$ and ${ }^{39} \operatorname{Ar}(\mathrm{n}, \alpha){ }^{36} \mathrm{~S}$ reactions yields valuable information for nuclear spectroscopy (e.g. width and spin of nuclear levels), but these reactions play also an important role in the nucleosynthesis network in the sulfur region. Due to the absence of experimental data, theoretical values were used so far in the network calculations. We transformed our $\sigma\left(E_{n}\right)$ values in reaction rates [5]. Strong discrepancies with the theoretical values $[6,7,8]$ were observed. Replacing these theoretical values by our experimental data significantly modifies the branchings at ${ }^{37} \mathrm{Ar}$ and ${ }^{39} \mathrm{Ar}$. In the case of carbon burning e.g., $87.3 \%$ of the reaction flow at ${ }^{37} \mathrm{Ar}$ passes now via the $(\mathrm{n}, \alpha)$ channel compared to $45.5 \%$ with the theoretical values. This results in a modification of the nucleosynthesis flow, influencing the s-process abundances of e.g. ${ }^{36} \mathrm{~S}$ and ${ }^{40} \mathrm{Ar}$.

\section{References}

1. C. Wagemans, M. Loiselet, R. Bieber, B. Denecke, D. Reher and P. Geltenbort, Nucl. Instr. Meth. A 397 (1997) pp. 22-25.

2. R. Firestone, Table of Isotopes (J. Wiley, New York, 1996).

3. R. Bieber et al., Nucl. Phys. A 647 (1999) pp. 3-11.

4. M. Asghar, A. Emsallem, E. Hagberg, B. Jonson and P. Tidemand-Petersson, Z. Phys. A 288 (1978) pp. 45-48.

5. G. Goeminne, C. Wagemans, J. Wagemans, O. Serot, M. Loiselet and M. Gaelens, Nucl. Phys. A 678 (2000) pp. 11-23.

6. S. Woosley and T. Weaver, Ann. Rev. Astr. Astrophys. 24 (1986) pp. 205-253.

7. T. Rauscher, Proc. Int. Symp. Nuclei in the Cosmos, Volos (Greece), Ed. Frontieres, Paris (1999) pp. 484-490.

8. S. Goriely, Proc. Int. Symp. on Capture Gamma-Ray Spectroscopy and Related Topics, Santa Fe (USA), AIP Conf. Proc. 529 (2000) pp. 287-294. 